\title{
LA TUTELA SOBRE LOS CATÓLICOS ORIENTALES EN LOS TERRITORIOS DE LA IGLESIA LATINA
}

\author{
Grzegorz Wojciechowski*
}

\begin{abstract}
Outside their own territories, the Eastern Catholic Churches adopt a variety of pastoral structures, such as eparchies or exarchates. Moreover, there are also parishes that bring together the followers of various Eastern Churches which do not reside within the given territory. The priests of Eastern Churches who exercise pastoral care over the followers, oftentimes participate and serve in the structures of the Latin Church as well. In order to be able to do so, they must have been granted bi-ritual faculties from Rome, the Holy See.
\end{abstract}

Key words: eparchy, territory administrative, Eastern Catholic Churches, pastoral care, territory ecclesiastical.

Territorialidad, según los cánones 12 y 13 del CIC’83 y 1491 del CCEO, es un criterio clasificador del ámbito de las leyes eclesiásticas, por esto puede ser territorial o personal. Presentando el término territorio nos referimos a un principio delimitador de las comunidades y circunstancias eclesiásticas, clero y fieles, que habiten en un determinado territorio (factor territorial), o sean organizadas en un grupo numeroso de fieles (factor personal) ${ }^{1}$.

* Associate Professor Hab., PhD, John Paul II Catholic University of Lublin, Faculty of Law, Canon Law and Administration, Institute of Canon Law.

${ }^{1}$ Cf. A. Viana, Territorialidad [Principio de], w: Diccionario General de Derecho Canónico, vol. VII, red. J. Otaduy, A Viana, Pamplona 2012, p. 557. 
Los movimientos migratorios hacen una fuerte preocupación por los problemas espirituales de los fieles emigrantes y de sus necesidades en el campo de la pastoral.

Ya el Concilio Vaticano II reconoció este problema, por eso encomienda a los obispos el cuidado especial de los fieles de otro rito: Para este fin también donde haya fieles de diverso rito, provea el Obispo diocesano a sus necesidades espirituales por sacerdotes o parroquias del mismo rito o por un vicario episcopal, dotado de facultades convenientes y, si es necesario, dotado incluso del carácter episcopal o que desempeñe por el mismo el oficio de ordinario de los diversos ritos. Pero si todo esto no pudiera compaginarse, según parecer de la Sede Apostólica, establézcase una jerarquía propia según los diversos ritos $(\mathrm{CD}, 23)$.

El problema presentado no es meramente teórico, pero también jurídico y pastoral. Necesidad de atención pastoral de la Iglesia subraya que los fieles no pueden quedarse sin los sacramentos. La aplicación de sus derechos y obligaciones, basados en la economía sacramental, se debe proporcionar en cualquier momento y en cualquier lugar, sin tener en cuenta siquiera el hecho de residir fuera de las estructuras del propio territorio de la Iglesia sui iuris².

Esta situación se relaciona principalmente con los fieles que pertenecen a las Iglesias orientales católicas, y que residen o se encuentren en el territorio de la Iglesia latina o fuero de su propio territorio.

La situación actual de emigración y el papel de la Iglesia ante la movilidad humana, parece muy interesante ver el tema de la atención pastoral de los fieles orientales que se encuentran en los territorios de la Iglesia latina, donde no está constituida su propia Jerarquía, quedando encomendados de este modo a la cura pastoral de los Ordinarios latinos. Como bien sabemos, dicha atención, aunque no exclusivamente, tiene su momento cumbre en la administración de los sacramentos y la vigilancia del sus propios ritos ${ }^{3}$.

De acuerdo con el can. $107 \$ 1$ de CIC y el canon $916 \$ 1$ de CCEO se presenta el propio párroco y el Ordinario a través de la residencia perma-

${ }^{2}$ Cf. R Hołubowicz, La atención pastoral de los fieles católicos orientales por parte de la Iglesia latina: administración de los sacramentos de la iniciación cristiana y el matrimonio, Cuadernos doctorales 24 (2010-2011), p. 146-147.

${ }^{3}$ Ibidem. 
nente o temporal en un territorio determinado ${ }^{4}$. Ellos, como los pastores a cargo de una comunidad de creyentes llevan frente a ellos la atención pastoral realizando la tarea de: enseñar, santificar y dirigir. Sin embargo, su poder es ejercido en virtud del oficio encomendado, y se refiere esencialmente sólo a los fieles de su propia Iglesia sui iuris. El Ordinario del lugar y el párroco latino en virtud de estas normas anteriormente mencionadas, no se puede considerar directamente como el ordinario o el pastor para los fieles orientales, que residen o se hallen en su territorio, y por el contrario ${ }^{5}$. Esto plantea importante cuestiones jurídicas y pastorales de los católicos orientales que residen en los territorios de la Iglesia latina. Ellos también, como miembros de la Iglesia: una y universal, necesitan la atención sacramental y sus propios pastores, para que, privados de una oportunidades permanentes o temporales puedan participar plenamente en la vida religiosa de su propia Iglesia sui iuris, teniendo garantía de recibir los bienes y gracias obtenidas a través de la Santa Iglesia. Para lograr este atención pastoral, el Código de Derecho para las Iglesias Orientales regula el estatus jurídico de los fieles de las Iglesias orientales católicas que se hallan o residen fuera del territorio de su propia Iglesia sui iuris, tanto en las zonas donde hay estructuras de su Iglesia, que carece de su propio sacerdote, como y en los lugares donde no se ha creado, incluso exarcado para los cristianos de la propia Iglesia sui iuris ${ }^{6}$.

El Decreto conciliar Christus Dominus en el numero 11 dice que cada uno de los Obispos, acentúa la Declaración concilias, a los que se ha confiado el cuidado de cada Iglesia particular, bajo la autoridad del Sumo Pontifice, como sus pastores propios, ordinarios e inmediatos, apacienten sus ovejas en el Nombre del Señor, desarrollando en ellas su oficio de enseñar, de santificar y de regir. Ellos, sin embargo, deben reconocer los derechos que competen legitimamente a los patriarcas o a otras autoridades jerárquicas. Por eso, los miembros del Colegio de los Obispos participan en la tutela de

${ }^{4}$ Cf. P. V. Pinto, Commentario al can. 916, en: Commento al Codice dei Canoni delle Chiese Orientali, P. V. Pinto (ed.), Città del Vaticano 2001, p. 788.

${ }^{5}$ Cf. J. Prader, Differenze fra il diritto matrimoniale del Codice latino e quello del Codice orientale che influiscono sulla validità del matrimonio, Ius Ecclesiae 5 (1993), p. 479.

${ }^{6}$ Cf. U. Nowicka, Opieka duszpasterska nad wiernymi Katolickich Kościotów Wschodnich na terytorium tacinskim, Seminare 28 (2010), p. 29. 
toda la Iglesia universal y de su propia Iglesia particular. De ahí los Obispos tienen que preocuparse no solamente a los fieles pertenecientes a su propia Iglesia sui iuris ${ }^{7}$, de acuerdo con el principio de sollicitudo omnium Ecclesiarum, se refiere a toda la Iglesia. El Código de 1983 y el Código oriental, como también el Decreto conciliar Orientalium Ecclesiarum, n. $4^{8}$ y Christus Dominus, n. $23^{9}$, señalan dentro de las obligaciones de los Obispos eparquíales preocupación por los fieles que pertenecen a las Iglesias sui iuris distintas de la suya, y que les son confiadas del mismo modo como los de sus propias diócesis. Por lo tanto el obispo es responsable, como un pastor, de todos los cristianos que residen en su territorio, ya sea de forma permanente o sólo temporalmente. Este principio fue expresado directamente en el canon $192 \$ 1$ CCEO: llenar su ministerio pastoral, el obispo de la eparquia debe hacerse cargo de todos los cristianos, confiados a su cuidado, sin importar su edad, posición, la nacionalidad o la Iglesia sui iuris. El canon análoga $383 \$ 1$ del Código latino no menciona en su contenido los fieles de otras Iglesias sui iuris, sin embargo requiere claramente del obispo, en el $\$ 2$ del mismo canon, remediar a las necesidades espirituales de los fieles de un rito diferente. Una manera de lograr este requisito es establecer para los fieles orientales: los sacerdotes, erigir las parroquias rituales o establecer el vicario episcopal. La tarea importante del Obispo eparquial, calificado por CCEO como una obligación grave, es también la preocupación por los fieles, lo que permite a los estos de otra Iglesia sui iuris observancia y desa-

${ }^{7}$ Cf. L. Sabbarese, Commento al can. 193, en: Commento al Codice dei Canoni delle Chiese Orientali, PV Pinto (ed.), Città del Vaticano 2001, p. 179.

${ }^{8}$ Por consiguiente, debe procurarse la protección y el incremento de todas las Iglesias particulares y, en consecuencia, establézcanse parroquias y jerarquías propias, allí donde lo requiera el bien espiritual de los fieles.

${ }^{9}$ Cf. L. Adamowicz, Katolicy wschodni w duszpasterstwie Kościoła tacińskiego w Polsce, w: Spotkania Cyrylometodiańskie. Międzynarodowa Konferencja Naukowa „Sacri canones - 20 lat doświadczeń”, pod red. K. Nitkiewicz, Sandomierz 2010, p. 97. Para este fin también donde haya fieles de diverso rito, provea el Obispo diocesano a sus necesidades espirituales por sacerdotes o parroquias del mismo rito o por un vicario episcopal, dotado de facultades convenientes y, si es necesario, dotado incluso del carácter episcopal o que desempeñe por el mismo el oficio de ordinario de los diversos ritos. Pero si todo esto no pudiera compaginarse, según parecer de la Sede Apostólica, establézcase una jerarquía propia según los diversos ritos. 
rrollo de su propio rito bajo la autoridad de los superiores de esta Iglesia ${ }^{10}$. Del mismo modo se lleva a cabo uno de los derechos fundamentales de los cristianos, a saber: el derecho del culto de Dios, de acuerdo con las normas de su propia Iglesia sui iuris, asi como seguir su propia forma de vida espiritual, sin embargo, compatibles con la doctrina de la Iglesia ${ }^{11}$.

La preocupación del legislador eclesiástico por la preservación del propio rito esta puesta en el canon $28 \$ 1$, que dice: un rito es el patrimonio litúrgico, teológico, espiritual y disciplinar extraido por la cultura y las circunstancias históricas de las naciones, que expresa de la manera en que yo creo, especificos para cada Iglesia sui iuris. Esta obligación canónica impuesta por el legislador esta derivada de la tradición apostólica y las obligaciones episcopales.

Las Iglesias orientales católicas, abarcan 24 diferentes Iglesias sui iuris, en los términos de un sistema administrativo, que se divide en: la Iglesia patriarcal, Arzobispal Mayor, Metropolitana sui iuris y otras Iglesias sui iuris $^{12}$. Los fieles que están fuera de estos territorios están agrupados en las estructuras como: eparquía o exarquia; pero no siempre. Hay lugares donde los fieles de un concreto rito sui iuris se mantendría sin dicha tutela de su propio pastor. Deliberadamente se utilizó para estas situaciones la regulación del can. $916 \$ 4-5$ CCEO describiendo la situación jurídica de los fieles que residen temporalmente o permanentemente en los territorios fuera de su propia Iglesia sui iuris ${ }^{13}$.

En dicha situación el legislador distingue dos hechos:

- los territorios en los que se estableció la estructura de una Iglesia sui iuris particular y

- los territorios en los que no se estableció la estructura de una Iglesia sui iuris particular.

Los territorios con estructura implica la existencia en un territorio de una jerarquía de determinada Iglesia oriental, tanto dentro como

${ }^{10}$ Cf. CCEO, can. $193 \$ 1$.

${ }^{11}$ CCEO, can. 17; cf. D. Salachas, Comenatrio al can. 17, en: Commento al Codice dei Canoni delle Chiese Orientali, P. V. Pinto (ed.), Città del Vaticano 2001, p 24-25; Nowicka, Opieka duszpasterska nad wiernymi..., p. 32.

${ }^{12}$ CCEO, can. 55-175, G. Wojciechowski, Ustrój hierarchiczny katolickich Kościotów wschodnich. Wybrane zagadnienia, Lublin 2011.

${ }^{13}$ CCEO, can. 916. 
fuera del propio territorio de la Iglesia sui iuris. Como ejemplo de esto se puede mencionar situación de Polonia, donde hay el Arzobispado Przemysko-Warszawskiej del rito bizantino-ucraniano. Los fieles de esta Iglesia están sujetos a los jerarcas de dicha Iglesia, en la persona del arzobispo Eugeniusz Popowicz (Archeparquía Przemyśl-Warszawa) y al obispo Włodzimierz Juszczak (eparquía Wrocław-Gdańsk) ${ }^{14}$. Puede suceder, sin embargo, la situación en la que, a pesar de la existencia de estructuras jerárquicas en un territorio particular faltara para una comunidad de los fieles su propio pastor ${ }^{15}$. La solución de este caso se encuentra en el can. $916 \$ 4$ CCEO: Si no hay una cura para los cristianos, una Iglesia sui iuris, el Obispo se nombrará pastor de la eparquía de otra Iglesia sui iuris, que se hará cargo de ellos como su propio pastor, pero con el consentimiento del Obispo eparquial nombrado párroco ${ }^{16}$.

Los territorios sin las estructuras y la jerarquía para los fieles de una Iglesia sui iuris oriental está prevista en el canon $916 \$ 5$ CCEO. El legislador distingue aquí las áreas incluidas en el territorio de la Iglesia patriarcal (o del Arzobispo Mayor - can. 152 CCEO) ${ }^{17}$ y la otra, por lo que mención explícitamente la conducta según el can. 101 CCEO. De conformidad con el can. $146 \$ 1$ CCEO territorio de la Iglesia, que se rige por el patriarca, que se extendió a las regiones en las que el rito se conserva la jurisdicción de esta Iglesia. De esta manera, por la voluntad del legislador, dentro del territorio de la Iglesia patriarcal en lugares donde no se ha establecido ni la eparquía, o incluso ni el exarcado, el Patriarca es así mismo eparca para estos fieles y por lo tanto tiene los mismos derechos y obligaciones que un eparca $^{18}$.

En cambio, cuando los territorios mencionados, se encuentran fuera de los límites de la Iglesia patriarcal o se refiere a los fieles de otra Iglesia sui iuris que no sea patriarcal, entonces - si se asume que en el territorio de referencia es sólo un jerarca de otra Iglesia sui iuris, con la jurisdicción

\footnotetext{
${ }^{14}$ Cf. Adamowicz, Katolicy wschodni w duszpsterstwie..., p. 98-103.

${ }^{15}$ Cf. Nowicka, Opieka duszpasterska nad wiernymi..., p. 33.

16 Ibidem, p. 34.

${ }^{17}$ Cf. P. Gafaell, L'territoriale ambito della giurisdizione dei Patriarchi orientali. Forma sulla Riflessi canonica del matrimonio, Ius Ecclesiae, 5 (1993), p. 253-259.

${ }^{18}$ Cf. Nowicka, Opieka duszpasterska nad wiernymi..., p. 34.
} 
necesaria - se le considera como jerarca propio de estos fieles, en la práctica y por lo general será Ordinario latino. De acurdo con el canon $916 \$ 5$ CCEO los fieles orientales que se encuentran en la diócesis de Roma y tengan su domicilio o residencia allá, tienen como su propia jerarquía el mismo Papa ${ }^{19}$.

En la situación cuando en un territorio habita el jerarca occidental junto con el jerarca oriental, y en este territorio se encuentra un grupo de fieles orientales pero de otra iglesia que la del jerarca oriental. En este caso, el jerarca que va tener obligación de la tutela pastoral seria este que será nombrado por la Santa Sede. Pero si se habla de los fieles de la Iglesia Patriarcal ${ }^{20}$ o de Arzobispo Mayor ${ }^{21}$, este quien elige uno u otro con el consentimiento de la Santa Sede. Por ejemplo, los ármenos residentes en Polonia y privados de su propio obispo, desde el 25 de octubre de 1946, están bajo la tutela pastoral del Arzobispo de Varsovia ${ }^{22}$.

De esto deriva que la atención pastoral sobre los fieles de las Iglesias católicas orientales nunca se quedan sin la tutela pastoral necesaria y sin su propia jerarquía. Sin embargo, cabe señalar que la asignación de los católicos orientales al Ordinario latino o a la jerarquía de otra Iglesia sui iuris no significa que automáticamente están sujetos al párroco del lugar. En virtud del can. $916 \$ 5$ CCEO para estos fieles no es dicho párroco aunque faltas estructuras de su propia Iglesia sui iuris. La resolución de esta situación esta en las normas de los dos Códigos y prevé la posibilidad de erigir parroquias personales, e incluso las diócesis personales ${ }^{23}$.

El Concilio Vaticano II para erigir unas circunstancias jurídicas rituales vio la necesidad de unas Iglesias particulares con el carácter ritual, don-

${ }^{19}$ Cf. D. Salachas - K. Nitkiewicz, Rapporti interecclesiali tra Cattolici orientali e Latini. Sussidio Canonico-pastoral, Roma 2007, p 76.

${ }^{20}$ En la actualidad, Iglesia patriarcal: la caldeos, coptos, armenios, maronitas, melquitas y sirios; cf. Wojciechowski, Ustrój hierarchiczny ..., p. 132.

${ }^{21}$ Las iglesias del Arzobispo Mayor: siro-malabar, syro-malancar, ucraniano y rumano; cf. Wojciechowski, Ustrój hierarchiczny..., p. 132.

${ }^{22}$ Cf. Nowicka, Opieka duszpasterska nad wiernymi..., p. 34; J. Krętosz, Wschodnie katolickie obrzadki w Polsce, Katowice 2008, p. 111; Adamowicz, Katolicy wschodni $w$ duszpsterstwie..., p. 98-99.

${ }^{23}$ Cf. Nowicka, Opieka duszpasterska nad wiernymi..., p. 35; Adamowicz, Katolicy wschodni w duszpsterstwie..., p. 101-102. 
de se incluirá los fieles del rito particular. De esta manera, se resuelve el problema de la presencia de varios obispos en un mismo territorio, pero permitiendo la existencia de varias diócesis de distintos ritos para atender las necesidades de los fieles ${ }^{24}$. Esta idea fue confirmada en la Instrucción de la Congregación para los Obispos Ecclesiae Imago sobre el ministerio pastoral de los obispos ${ }^{25}$.

De acuerdo con estas normativas, el legislador eclesial, adoptando como una norma la territorialidad de la diócesis, no trata el territorio como elemento constitutivo de una Iglesia particular ${ }^{26}$. Por lo tanto, en el orden canónico se señala cuatro tipos de ámbitos eclesiales de carácter personal: diócesis personales ${ }^{27}$, Prelatura Personal ${ }^{28}$ y otros dos: los ordinariatos castrenses y los ordinariatos para los fieles orientales, pero no previstos expresamente en el Código ${ }^{29}$.

Pero, para erigir las unidades eclesiales en un mismo territorio debe entenderse como una excepción de la regla de que en un territorio debe haber una sola jerarquía. El legislador en el Código de 1983 en el canon $372 \$ 2$ prevé la erección en un mismo territorio de entidades separadas por el rito. Son ellos una verdadera comunidad de creyentes, establecidas según un criterio personal, y no por el criterio de residencia o de estancia.

${ }^{24}$ Cf. Concilio Vaticano II, Dec. Christus Dominus, n. 23: Para este fin también donde haya fieles de diverso rito, provea el Obispo diocesano a sus necesidades espirituales por sacerdotes o parroquias del mismo rito o por un vicario episcopal, dotado de facultades convenientes $y$, si es necesario, dotado incluso del carácter episcopal o que desempeñe por el mismo el oficio de ordinario de los diversos ritos. Pero si todo esto no pudiera compaginarse, según parecer de la Sede Apostólica, establézcase una jerarquía propia según los diversos ritos; http://www.vatican. va/archive/hist_councils/ii_vatican_council/documents/vat-ii_decree_19651028_christus-dominus_en.html (2016-08-24).

${ }^{25}$ Cf. Congregatio pro Episcopis, Directorium Ecclesiae imago de pastorali ministerio Episcoporum, 22.02.1973, Typis Polyglottis Vaticanis 1973, n. 172; Nowicka, Opieka duszpasterska nad wiernymi..., p. 35.

${ }^{26}$ Cf. J. L. Gutiérrez, Commento al can. 372, en: Código de Derecho Canónico (1983). Edición bilingüe y anotada a cargo del Instituto Martín de Azpilcueta, Pamplona 1992 , p. 307.

${ }^{27} \mathrm{CIC}$, can. $372 \$ 2$.

${ }^{28}$ CIC, can. 294-297.

${ }^{29}$ Cf. L. Lorusso, Gli orientali cattolici e i pastori latini. Problematiche e norme canoniche, Kanonika II, Roma 2003, p. 83, Nowicka, Opieka duszpasterska nad wiernymi..., p. 35 . 
Por la norma dichos sujetos están establecidas por la Santa Sede, después de escuchar la opinión de la Conferencia Episcopal. Salalchas subraya que la colocación de dicha norma es salir delante de problema de la migración de los fieles orientales a los territorios tradicionalmente latinos. Por otra parte en Código oriental es dictado por el hecho de que en Oriente desde hace siglos fueron creadas por la Santa Sede, las diócesis latinas, por lo tanto, la norma sería simplemente innecesaria ${ }^{30}$.

Los dos Códigos, latino y oriental, después de la sanción del principio general de territorialidad de la parroquia o extender en su alcance a todos los fieles de un territorio determinado, prevén la posible erección de la parroquia personal ${ }^{31}$. Una de las razones de su erección es el mantenimiento de un rito, de acuerdo con las normas del CCEO sobre su adscripción a una Iglesia sui iuris que en algunos casos la norma requiere la consulta del consejo sacerdotal, en concreto del Obispo eparquial ${ }^{32}$. Del mismo modo el canon latino $383 \$ 2$ decide que si hay en su diócesis fieles de otro rito, provea a sus necesidades espirituales mediante sacerdotes o parroquias de este rito, o mediante un Vicario episcopal.

Por ejemplo: en Polonia, hay las parroquias personales para los católicos orientales de la Iglesia sui iuris de ármenos. Hay que tener en cuenta que ellas forman una parte integral con la diócesis latina y sus sacerdotes pertenecen al clero diocesano latino ${ }^{33}$. A su vez, los fieles de dichas parroquias personales pertenecen a su propia Iglesia sui iuris, que es coherente con la norma expresada en el canon oriental numero 38: Los cristianos de las Iglesias Orientales, incluidos aquellos que han sido confiados al cuidado de la Jerarquía o el pastor de otra Iglesia sui iuris, pertenecen definitivamente a su propia Iglesia sui iuris.

Este canon está dictado por la perspectiva de la fidelidad a la propia Iglesia, tendiendo como el fin la protección fundamental y desarrollo de su propio rito, en cualquier lugar - en especial donde se encuentran otros

${ }^{30}$ Cf. D. Salachas, Problematiche interrituali nei due Codici orientale e latino, Apollinaris 75 (1994), p. 650; Nowicka, Opieka duszpasterska nad wiernymi..., p. 36.

${ }^{31} \mathrm{CIC}$, can. 518, CCEO can. $280 \$ 1$.

${ }^{32}$ Cf. Nowicka, Opieka duszpasterska nad wiernymi..., p. 36.

${ }^{33}$ Cf. Adamowicz, Katolicy wschodni w duszpsterstwie..., p. 99; Salachas - Nitkiewicz, Rapporti interecclesiali..., p 78. 
ritos como subraya el can. $28 \$ 1$ del Código oriental; también con el fin de la perspectiva de la tutela pastoral de los fieles que se encuentran fuera del territorio de su propia Iglesia, sobre todo en los territorios latinos ${ }^{34}$.

En este punto, es necesario acentuar que no sólo la adscripción a las parroquias personales de un rito creado en territorio de otra Iglesia sui iuris, sino también la participación real en la vida religiosa y sacramental en el servicio pastoral de la Iglesia de otro rito no constituye el cambio de su propio rito; el can. $112 \$ 2$ del CIC dice que La costumbre, por prolongada que sea, de recibir los sacramentos según el rito de alguna Iglesia ritual autónoma no lleva consigo la adscripción a dicha Iglesia. Así pues, los católicos en general incluso si residen de forma permanente en una parroquia o en una institución eclesial, siempre permanecen suscritos a su propia Iglesia sui iuris ${ }^{35}$.

Los sacramentos de la iniciación cristiana están vinculados. En la tradición oriental esta vinculación es más perceptible. En Oriente en la celebración de los dos primeros, bautismo y crismación, siempre se administran en el mismo acto litúrgico. Se aconseja que se los complete con la celebra-

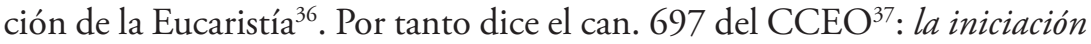
sacramental en los misterios de la salvación se complementa con la recepción de la divina Eucaristía.

Considerando el sacramento del bautismo, como puerta a la concreta comunidad sui iuris, importante es el tema de la adscripción a una Iglesia. La incorporación a la Iglesia por el bautismo inserta al cristiano en una comunidad cristiana concreta y produce automáticamente una vinculación canónica con una Iglesia sui iuris llamada adscripción, distinta de la inscripción o prueba escrita de la vinculación. Por ella, el cristiano se une o se vincula a una Iglesia particular en la que vive y celebra la fe, en la que descubre el misterio cristiano siempre fascinante, y donde organizadamente se expresa la Iglesia como Pueblo de Dios y el cristiano como miembro vivo $^{38}$. La pertenencia a una determinada Iglesia sui iuris es efecto de un

${ }^{34}$ Cf. Salachas, Problematiche interrituali..., p. 648.

${ }_{35}$ Cf. Nowicka, Opieka duszpasterska nad wiernymi..., p. 36.

${ }^{36}$ Cf. A. Celeghin, L'Iniziazione Cristiana nel CIC 1983. Prima parte: alcuni aspetti generali, Periodica 84 (1995), p. 31-41.

${ }^{37}$ Cf. D. Salachas, Comenatrio al can. 697, en: Commento al Codice dei Canoni delle Chiese Orientali, P. V. Pinto (ed.), Città del Vaticano 2001, p. 837.

${ }^{38}$ Cf. Hołubowicz, La atención pastoral..., p. 165. 
acto de libre voluntad, de recepción de un sacramento del bautismo. Uno se hace miembro de la Iglesia universal por recepción de este sacramento en una concreta Iglesia a la que queda adscrito, prescindiendo del rito litúrgico en el que se celebró el bautismo.

En primer lugar, parece que apropiado que el Ordinario latino, antes de establecer la parroquia personal y designar a un pastor para los fieles católicos orientales, se ponga en contacto con el Jerarca de la esta Iglesia sui iuris a la que pertenecen dichos fieles ${ }^{39}$. Eso está baso en el can. $193 \$ 3$ del CCEO, según el cual los obispos eparquiales que estos sacerdotes, pastores o establecer Sincelos a la preocupación por los cristianos Iglesia Patriarcal, de acuerdo con los patriarcas, les permiten llegar a un acuerdo y trabajar con su acuerdo con el poder de su propia cuenta, lo antes posible después de la notificación de la Santa Vea, si los Patriarcas en cualquier caso no estarian de acuerdo, la cuestión se presentó a la Santa Sede.

Aunque en el Código latino no encontramos una disposición jurídica en este asunto, sin embargo el canon oriental se refiere, indirectamente, a los obispos latinos, bajo el principio establecido en el can. 19 de CIC, que recuerda la aplicación de las leyes dictadas en un caso similar llamada vacio legal $l^{40}$. Por otra parte, tal obligación del Ordinario parece ser una consecuencia del principio expresado en el can. 38 del Código oriental en el que la adscripción a su propia Iglesia sui iuris, sin importar el hecho de estar bajo la tutela pastoral de la Jerarquía o párroco de otro rito ${ }^{41}$.

La preocupación por los fieles católicos orientales que están obligados de entender el patrimonio especial de su propio rito oriental, es la segunda obligación de los obispos. Esta preocupación esta dispuesta en el can. 41 del $\mathrm{CCEO}^{42}$ : los cristianos de cada Iglesia sui iuris, incluso la Iglesia latina que, en virtud de su cargo, ministerio o tarea a menudo se reunió con los cristianos de otra Iglesia sui iuris, deben ser instruidos cuidadosamente acerca de la Iglesia en relación con la gravedad de la oficina, ministerio o tareas que llenar.

${ }^{39}$ Cf. Nowicka, Opieka duszpasterska nad wiernymi..., p. 37.

${ }^{40}$ Cf. Salachas - Nitkiewicz, Rapporti interecclesiali..., p 78.

${ }^{41}$ Cf. D. Salachas, Comenatrio al can. 38, en: Commento al Codice dei Canoni delle Chiese Orientali, P. V. Pinto (ed.), Città del Vaticano 2001, p 50-51.

${ }^{42}$ Cf. Idem, Comenatrio al can. 41, en: Commento al Codice dei Canoni delle Chiese Orientali, P. V. Pinto (ed.), Città del Vaticano 2001, p 54. 
Aunque no encontramos un canon latino análogo, pero no hay ninguna duda de que este hecho no exime a los obispos latinos de hacer esfuerzos para educar a los que quieren servir pastoralmente a los fieles que pertenecen a los ritos orientales ${ }^{43}$. Esto se basa en el contenido del numero 6 del Decreto Orientalium Ecclesiarum.

Innegable bondad que fluye del hecho de que la erección de las parroquias personales rituales no siempre puede llevar a cabo ese camino. Sucede que el número de los fieles pertenecientes a la Iglesia oriental sui iuris, y que residen en un territorio determinado es tan pequeño que la creación de una parroquia personal en la práctica también podría experimentar grandes dificultades y ha impedido que el ministerio pastoral fructífera. El peligro esta también en una multiplicidad de ritos en el territorio latino. No carece de importancia la falta de recursos apropiados necesarios para establecer una parroquia personal. En tales situaciones, ambos Códigos prevén el establecimiento de un vicario episcopal para los fieles rituales ${ }^{44}$.

Según el canon 246 del Código para las Iglesias orientales una de las formas de la tutela pastoral de los fieles orientales pertenecientes a una Iglesia sui iuris residentes en los territorios latino dicha norma menciona el derecho del Obispo de nombrar a un vicario episcopal para una circunstancia especial ${ }^{45}$.

El canon oriental es mas preciso del latino, ya que el latino no menciona pertenecía sui iuris del vicario episcopal que servirá a los fieles orientales, mientras que el oriental deja libertad en la elección el Syncel, que puede ser designado como el sacerdote de otra eparquía, o incluso de otra Iglesia sui iuris ${ }^{46}$. Sin embargo, siempre bajo el consentimiento y la aprobación de su obispo eparquial ${ }^{47}$. Criterio de su nombramiento tiene carácter de eficiente gobierno en la diócesis, y dicha norma en este caso es opcional. Por lo tanto, será necesario y conveniente, a juicio del Obispo eparquial,

${ }^{43}$ Cf. Nowicka, Opieka duszpasterska nad wiernymi..., p. 37.

${ }^{44}$ Ibidem, p. 38.

${ }^{45}$ Cf. Concilio Vaticano II, Christus Dominus, n. 27; http://www.vatican.va/archive/ hist_councils/ii_vatican_council/documents/vat-ii_decree_19651028_christus-dominus_ en.html (2016-08-24).

${ }^{46}$ Cf. CCEO, can. $247 \$ 4$.

${ }^{47}$ Cf. L. Sabbarese, Commento al can. 247, en: Commento al Codice dei Canoni delle Chiese Orientali, P. V. Pinto (ed.), Città del Vaticano 2001, p. 222-223. 
decidir si el vicario episcopal en la diócesis es necesario y deseable. Entre los criterios que pueden indicar una necesidad concreta, los cánones 246247 consideran la presencia en dicho territorio de los fieles orientales, o la petición de un Jerarca oriental sui iurs. El alcance de sus obligaciones debe ser especificado en el decreto de nombramiento ${ }^{48}$.

Según la voluntad del legislador el vicario episcopal tiene la misma potestad ordinaria, que la pose por el derecho el vicario general con la única diferencia de que esta limitada en relación a los fieles orientales, para los que fue nombrado, y - como subraya canon oriental can. $248 \$ 1$ - exceptuadas cuantas gestiones el Obispo se hubiera reservado a si mismo o al Vicario general, o que según el derecho requieren mandato especial del Obispo. De este modo el vicario episcopal tiene la potestad de régimen vicaria. También es esto la potestad de régimen ordinario, ya que es la que va aneja de propio derecho a un oficio ${ }^{49}$; y es delegada, ya que se le concede a una persona por si misma, y no en razón de su oficio, sino gracias al obispo diocesano ${ }^{50}$.

Los fieles laicos por la migración buscan cada vez más posibilidades de profesar su tradición espiritual a parte de territorio donde se encuentran. Buscan también otras formas de vivir su fe y su espiritualidad. La Iglesia responde a esas necesidades organizando una pastoral especializada, realizada en diferentes estructuras eclesiásticas delimitadas por el territorio.

Los Códigos, oriental y latino, mencionan varios derechos de los fieles que tienen que ser realizados por parte de responsables de sus Iglesias en cuestión de la pertenencia a la comunidad eclesial. Entre ellos hay que señalar: la realización de una vida santa, la ayuda de sus pastores en cuanto a los bienes espirituales - Palabra de Dios y sacramentos, la adoración de Dios o la educación cristiana. Su aplicación se hace particularmente difícil en el caso de las personas que en virtud de las diferentes situaciones de la vida permanecen de forma permanente o incluso temporalmente fuera de su propia iglesia. El legislador establece una serie de normas que están diseñadas para proporcionarles atención pastoral adecuada, independientemente de

${ }^{48}$ Cf. Nowicka, Opieka duszpasterska nad wiernymi..., p. 39.

${ }^{49}$ Cf. CIC, can. $131 \$ 1$; CCEO, can. $981 \$ 1$.

${ }^{50}$ Cf. L. Sabbarese, Commento al can. 248, en: Commento al Codice dei Canoni delle Chiese Orientali, P. V. Pinto (ed.), Città del Vaticano 2001, p. 224-225. 
su lugar de residencia ${ }^{51}$. Los laicos pueden integrarse en esas comunidades, cooperar en la misión de la Iglesia y participar activamente en las obras apostólicas para el bien de todo el Pueblo de Dios. Sin embargo su aplicación, es necesario tener en cuenta la posibilidad de que la tutela de unos latinos puede causar el convertimiento de ellos al rito latino, por eso hay que tener en cuenta un mayor respeto al cuidado del rito oriental y la frecuente oportunidad de practicar y preservar la tradición de su propio rito.

\section{REFERENCES:}

Adamowicz L., Katolicy wschodni w duszpasterstwie Kościota tacińskiego w Polsce, w: Spotkania Cyrylometodiańskie. Międzynarodowa Konferencja Naukowa „Sacri canones - 20 lat doświadczeń”, pod red. K. Nitkiewicz, Sandomierz 2010, s. 97-123.

Celeghin A., L'Iniziazione Cristiana nel CIC 1983. Prima parte: alcuni aspetti generali, Periodica 84 (1995), p. 31-75.

Código de Cánones de las Iglesias Orientales. Edición bilingüe comentada a cargo de la Universidad Pontificia de Salamanca, Madrid 1994.

Código de Derecho Canónico (1983). Edición bilingüe y anotada a cargo del Instituto Martín de Azpilcueta, Pamplona 1992.

Concilio Vaticano II, Decr. Christus Dominus, http://www.vatican.va/archive/ hist_councils/ii_vatican_council/documents/vat-ii_decree_19651028_christus-dominus_en.html (2016-08-24).

Concilio Vaticano II, Decr. Orientalium Ecclesiarum, http://www.vatican.va/archive/hist_councils/ii_vatican_council/documents/vat-ii_

decree_19641121_orientalium-ecclesiarum_sp.html (2016-08-24).

Congregatio pro Episcopis, Directorium Ecclesiae imago de pastorali ministerio Episcoporum, 22.02.1973, Typis Polyglottis Vaticanis 1973.

Gafaell P., L'territoriale ambito della giurisdizione dei Patriarchi orientali. Forma sulla Riflessi canonica del matrimonio, Ius Ecclesiae, 5 (1993), p. 245-268.

Gutiérrez J. L., Commento al can. 372, en: Código de Derecho Canónico (1983). Edición bilingüe y anotada a cargo del Instituto Martín de Azpilcueta, Pamplona 1992, p. 307.

${ }^{51}$ Zob. K. Nitkiewicz, Katolickie Kościoty Wschodnie. Kompendium prawa, Sandomierz 2014, p. 99. 
Hołubowicz R., La atención pastoral de los fieles católicos orientales por parte de la Iglesia latina: administración de los sacramentos de la iniciación cristiana y el matrimonio, Cuadernos doctorales 24 (2010-2011), p. 143-242.

Krętosz J., Wschodnie katolickie obrządki w Polsce, Katowice 2008.

Lorusso L., Gli orientali cattolici e i pastori latini. Problematiche e norme canoniche, Kanonika II, Roma 2003.

Nitkiewicz K., Katolickie Kościoty Wschodnie. Kompendium prawa, Sandomierz 2014.

Nowicka U., Opieka duszpasterska nad wiernymi Katolickich Kościotów Wschodnich na terytorium tacińskim, Seminare 28 (2010), p. 29-40.

Pinto P. V., Commentario al can. 916, en: Commento al Codice dei Canoni delle Chiese Orientali, P. V. Pinto (ed.), Città del Vaticano 2001, p. 788.

Prader J., Differenze fra il diritto matrimoniale del Codice latino e quello del Codice orientale che influiscono sulla validità del matrimonio, Ius Ecclesiae 5 (1993), p. $469-494$.

Sabbarese L., Commento al can. 193, en: Commento al Codice dei Canoni delle Chiese Orientali, P. V. Pinto (ed.), Città del Vaticano 2001, p. 179.

Sabbarese L., Commento al can. 247, en: Commento al Codice dei Canoni delle Chiese Orientali, P. V. Pinto (ed.), Città del Vaticano 2001, p. 222-223.

Sabbarese, Commento al can. 248, en: Commento al Codice dei Canoni delle Chiese Orientali, P. V. Pinto (ed.), Città del Vaticano 2001, p. 224-225.

Salachas D. - Nitkiewicz K., Rapporti interecclesiali tra Cattolici orientali e Latini. Sussidio canonico-pastoral, Roma 2007.

Salachas D., Comenatrio al can. 17, en: Commento al Codice dei Canoni delle Chiese Orientali, P. V. Pinto (ed.), Città del Vaticano 2001, p 24-25.

Salachas D., Comenatrio al can. 38, en: Commento al Codice dei Canoni delle Chiese Orientali, PV Pinto (ed.), Città del Vaticano 2001, p 50-51.

Salachas D., Comenatrio al can. 41, en: Commento al Codice dei Canoni delle Chiese Orientali, PV Pinto (ed.), Città del Vaticano 2001, p 54.

Salachas D., Comenatrio al can. 697, en: Commento al Codice dei Canoni delle Chiese Orientali, P. V. Pinto (ed.), Città del Vaticano 2001, p. 837.

Salachas D., Problematiche interrituali nei due Codici orientale e latino, Apollinaris 75 (1994), p. 635-690.

Viana A., Territorialidad [Principio de], w: Diccionario General de Derecho Canónico, vol. VII, red. J. Otaduy, A Viana, Pamplona 2012, p. 557-562.

Wojciechowski G., Ustrój hierarchiczny katolickich Kościotów wschodnich. Wybrane zagadnienia, Lublin 2011. 
